\title{
A UML 2 Profile for Business Process Modelling *
}

\author{
Beate List and Birgit Korherr \\ Women's Postgraduate College for Internet Technologies \\ Institute of Software Technology and Interactive Systems \\ Vienna University of Technology \\ \{list, korherr\}@wit.tuwien.ac.at \\ http://wit.tuwien.ac.at
}

\begin{abstract}
Current UML Profiles for Business Process Modelling realise a narrow focus of the process, and capture the process flow on a low level of detail. They do not provide a comprehensive coverage of theoretical aspects. In this work, we have designed a UML 2 Profile for Business Process Modelling that provides two complementary perspectives, focussing on the business process context (e.g. goals, measures, products, customers, etc.) as well as on the detailed business process flow. Therefore, the profile presents a business process in a very comprehensive way. It is tested with an example business process.
\end{abstract}

\section{Introduction}

Business processes are often the starting point for software development and define requirements for software systems to be designed. Research and industry have addressed the alignment of business processes and IT only marginally. Most software developers are not aware of business processes or are not able to read the models, as different modelling languages with different diagrams and notations are used in both domains. In order to overcome this gap, we have developed a UML 2 Profile for Business Process Modelling (BPM), with the goal:

- To provide business process models to software developers in a wellknown notation (Reuse of the UML notation).

- To present business process models to software developers through UML tools (Reuse of UML tools).

- To develop a meta-model that covers comprehensive aspects of business process theory, including business process context.

UML profiles provide an extension mechanism for building UML models for particular domains. None of the existing UML profiles for business process modelling $[1,6,7,14,15]$ cover business process theory systematically. They realise a narrow focus of the process, and capture the process flow on a low level of detail. In contrast,

\footnotetext{
* This research has been funded by the Austrian Federal Ministry for Education, Science, and Culture, and the European Social Fund (ESF) under grant 31.963/46-VII/9/2002.
} 
we cover business process theory in the UML 2 profile for BPM comprehensively. As a basis for the UML 2 profile, we have developed a meta-model that provides two complementary perspectives: the business perspective and the sequence perspective. The business perspective presents the business process from a wide angle. Software developers will get a full understanding of the process without working through the complex process logic. The business perspective provides a model that gives a comprehensive understanding of the process, as it describes the major business process characteristics, such as goals and their measures, the deliverables, the owner, the type and the customer.

The sequence perspective refines the business perspective and describes the detailed flow of the process. It can utilise any business process modelling language, e.g. the Event-driven Process Chain [13], or the Business Process Modelling Notation [2]. A detailed description of the sequence perspective is out of the scope of this paper.

The contribution of the UML 2 profile for BPM is:

- It provides business process models to software developers in UML notation. As software systems support the business processes of an organisation, the profile represents the business context and business requirements to software developers in a formal and well-known modelling notation.

- The profile can support the elicitation of requirements from the business process models for the software systems to be developed. Deriving requirements from the business process models ensures a business-goal oriented software development.

- The profile can be integrated into the Computation Independent Model (CIM) of the Object Management Group's (OMG) Model Driven Architecture (MDA) [11] approach. Because the CIM model is a business model capturing the requirements of the software systems and is traceable to code, the integration of the UML profile can improve the quality of the requirements and the design of the software. The profile is raising the level of abstraction at which software development starts.

- The UML 2 profile for BPM can be easily extended and mapped to Business Process Execution Languages (BPEL). Mapping tools are able to take the business processes models developed in a UML tool and convert them to the correct BPEL, and vice versa. Thus, high productivity will be resulting, even if the underlying technology changes.

- The profile facilitates the seamless integration of already available business process models into a UML tool, because there is no additional modelling effort required.

- It could abandon Business Process Modelling tools, as almost all UML tools support UML profiles.

- The profile integrates business process models into the standard software development environment and can be seen as a further step towards bridging the gap between business process engineering and software engineering.

Based on the requirements of business process models in Section 2, we have developed a meta-model for the UML 2 profile for BPM in Section 3. The profile is described in Section 4 and tested with an example business process in Section 5. Related work is presented in Section 6. 


\section{Requirements - What must a Business Process Model Capture?}

Davenport, Hammer and Champy created with business process reengineering a new discipline at the beginning of the 1990ies and provided the theoretical concept for business process modelling. So far, in the business process modelling community attention has only been given to the modelling of certain aspects of processes (e.g. roles, activities, interactions). These aspects are represented for example in the Business Process Modelling Notation [2], the Event-driven Process Chain [13], the UML 2 Activity Diagram [9], or the Role Activity Diagram [12]. But there are a lot of other aspects including the business process context that should be also represented in a model.

A business process is defined as a "group of tasks that together create a result of value to a customer" [3]. Its purpose is to offer each customer the right product or service (that is, the right deliverable), with a high degree of performance measured against cost, longevity, service and quality [5]. The term customer should be used in an extended meaning. It can literally be simply a customer, but it can also be another process in the environment that is external to the company, such as a partner or subcontractor. Thus, a customer can be an internal or external role that receives products or services from a business process. An external customer is outside of the organisation, while the internal customer is part of the organisation.

Three types of business process are differentiated: core, support and management processes [12]. Core processes concentrate on satisfying external customers. They directly add value to the organisation. They respond to a customer request and generate customer satisfaction. Support processes concentrate on satisfying internal customers. They might add value to the customer indirectly by supporting a core business process. Management processes concern themselves with managing the core processes or the support processes, or the concern themselves with planning at the business level.

Functional structures have functional managers, and business processes have a similar concept for management, namely the process owner. He or she is an individual concerned with the successful realisation of a complete end-to-end process, the linking of tasks into one body of work, and making sure that the complete process works together [3]. Often these tasks are delegated and the process owner is focused on measuring the achievement of goals and initiate actions if necessary. Therefore, this person should be in a very powerful position, especially when she / he is the owner of a core business process.

Business processes support the achievement of enterprise goals in an organisation. Process goals support enterprise goals. The achievement of goals must be measured either by qualitative or quantitative measures. Measures aim at reaching a to-be-value or target value and are very important for business process improvement. "Measurements are the key. If you cannot measure it, you cannot control it. If you cannot control it, you cannot manage it. If you cannot manage it, you cannot improve it." [4].

Thus, beside activities and roles there are a lot of other aspects to be included into a business process model e.g. customers, process owners, process types, deliverables, goals and measures. And if there is a need for more things to be integrated into a business process model, feel free to make an extension! 


\section{The Business Process Modelling (BPM) Meta-Model}

Business process models need to express a lot of aspects. Capturing all available process characteristics in one model will completely overload it. Therefore, we have developed a business process meta-model that provides two complementary perspectives: a business perspective and a sequence perspective. The Business Perspective is an external perspective of the business process. It presents a general view of the process and describes its major characteristics e.g. the goals, the deliverables, or the customer at a glance. The Sequence Perspective provides the details of the process. It is an internal perspective and describes the process flow in detail, e.g. the order of tasks, the roles that perform the tasks, or the resources created. The perspectives of this business process modelling meta-model were inspired by Jacobson et al. [5], who proposed two perspectives for business process modelling as well. All other concepts of our approach are fully different.

\subsection{Business Perspective}

The business perspective provides the most important characteristics for describing a business process without showing its detailed flow. Software developers, who do not know or do not need to know the process in detail, will get a full understanding of the process without working through the complex process logic. The business perspective can be seen as a starting point for getting to know a business process or as an end in itself. Such a perspective is not provided by any state-of-the art process modelling language. Therefore, we have developed a meta-model (Fig. 1) capturing the major characteristics of a business process.

The meta-model of the business perspective (Fig. 1) presents the business process in relation to other process characteristics. A Business Process can be either a Core Process, a Support Process or a Management Process. A core process is either independent from support processes or supported by one or more support processes, which in turn support one or more core processes. A business process satisfies one or more Customers, who can be either External or Internal. External customers are outside of an organisation. Internal customers are part of the organisation and represent other groups or departments. External customers relate to core processes and internal customers relate to support or management processes. A Detailed Process Diagram describes each business process and can be seen as a link to the sequence perspective. A business process may be also composed of other business processes (or subprocesses), which in turn may be part of other business processes.

A Process Owner is responsible for one or more business processes. Each business process generates one or more Deliverables, which are either Services or Products. Each business process must achieve one or more Process Goals, which in turn support one or more Enterprise Goals. Concrete Measures describe the achievement of Goals, both process and enterprise goals. Each measure has a To Be Value assigned, which is sometimes also called a target value, and should be reached by each process instance. A Unit is also assigned to one or more measures. Measures judge the quality of goals and can be either Qualitative or Quantitative. 


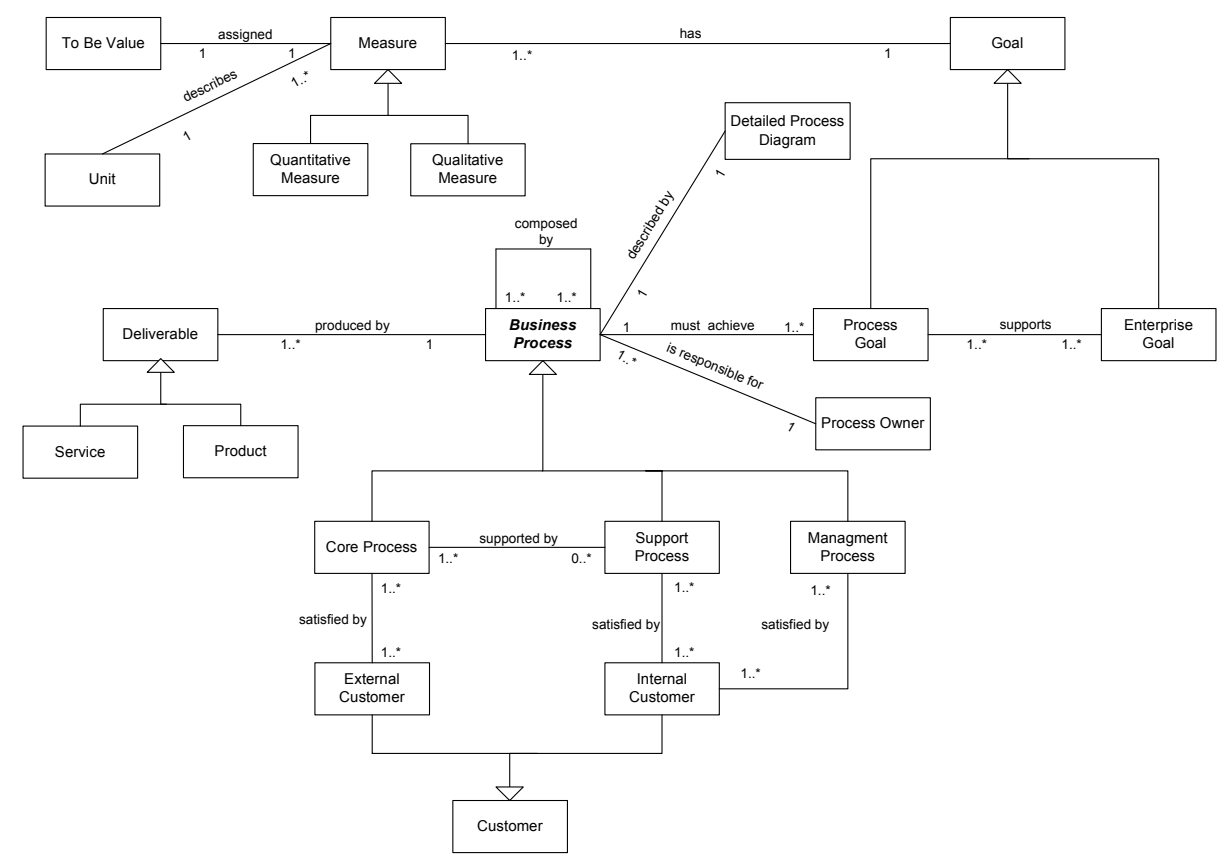

Fig. 1. Meta-Model of the Business Perspective

\subsection{Sequence Perspective}

The sequence perspective provides a detailed flow of the business process. Today, there are a lot of meta-models and diagrams (based on meta-models) for business process or workflow modelling available, e.g. the Business Process Definition MetaModel [10], the Business Process Modelling Notation [2], the Event-driven Process Chain [13], the UML 2 Activity Diagram [9], the Role Activity Diagram [12]etc. Therefore, we have decided not to design 'yet another meta-model', but rather to integrate a well-established one. This can foster the acceptance of this profile in general, and simplify the integration of already available process models into a UML tool in particular. Thus, we have decided to keep the meta-model of the sequence perspective open for the special requirements and the choice of the process modeller. Process models are often available in a lot of modelling tools (e.g. ARIS Toolset, MS Visio, Adonis, etc). This facilitates the integration of already available process models into a UML tool without additional modelling effort. In contrast, meta-models that have no sufficient tool support require modelling from scratch. A detailed description of the sequence perspective is out of the scope of this paper, as it depends on the specific preference for a business process modelling diagram of the organisation. 


\section{The UML 2 Profile for Business Process Modelling}

In this section, we describe the UML 2 profile for BPM. It is based on the business perspective of the BPM meta-model. UML offers a possibility to extend and adapt its meta-model to a specific area of application through the creation of profiles. UML profiles are UML packages with the stereotype «profile». A profile can extend a meta-model or another profile [9] while preserving the syntax and semantic of existing UML elements. It adds elements which extend existing classes. UML profiles consist of Stereotypes, Constraints and Tagged Values.

A stereotype is a model element defined by its name and by the base class(es) to which it is assigned. Base classes are usually meta-classes from the UML metamodel, for instance the meta-class «Class», but can also be stereotypes from another profile. A stereotype can have its own notation, e.g. a special icon.

Constraints are applied to stereotypes in order to indicate restrictions. They specify pre- or post conditions, invariants, etc., and must comply with the restrictions of the base class [9]. Constraints can be expressed in any language, such as programming languages or natural language. We use the Object Constraint Language (OCL) [8] in our profile, as it is more precise than natural language or pseudocode, and widely used in UML profiles.

Tagged values are additional meta-attributes assigned to a stereotype, specified as name-value pairs. They have a name and a type and can be used to attach arbitrary information to model elements.

The UML 2 profile for BPM creates an overview model in order to describe the major characteristics of business processes. It extends the meta-class "Class», the meta-class «Property» and the meta-class «Actor». In Fig. 2 we show a part of the UML 2 meta-model related to the classifier concept of UML 2 (light) to illustrate how the stereotypes we designed (dark) fit into to the existing UML 2 meta-model.

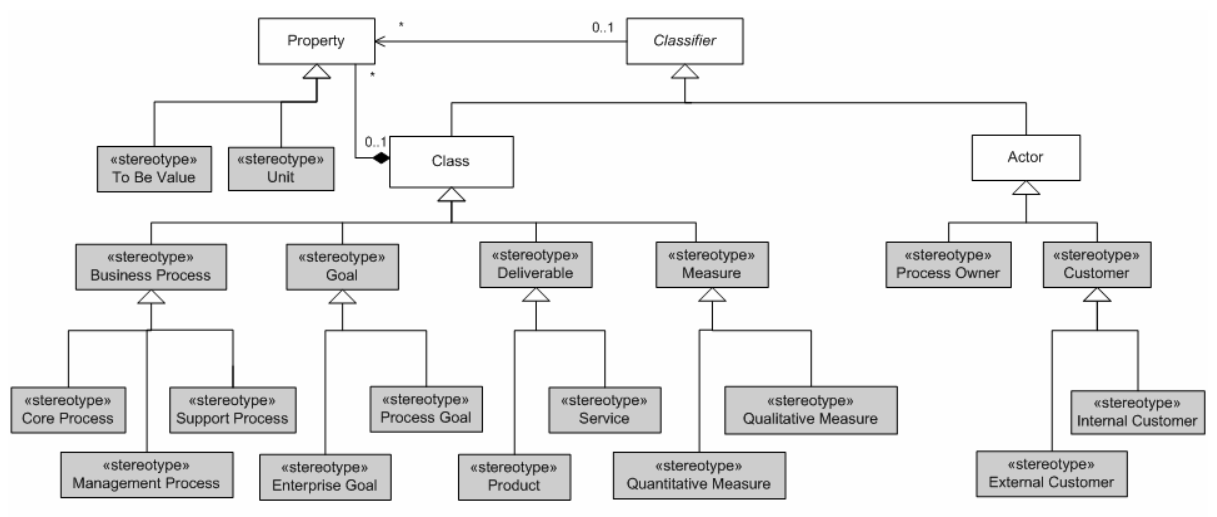

Fig. 2. Extending the UML2 Meta-Model with Stereotypes for BPM

In the UML 2 profile for BPM, we use the classes Class and Actor as base classes for all stereotypes. The OMG has defined a class as "a set of objects that share the same specifications of features, constraints, and semantics. The purpose of a class is 
to specify a classification of objects and to specify the features that characterize the structure and behavior of those objects." [9]. Therefore, classes are appropriate for business processes and their characteristics. An actor is used in UML 2 for modelling roles interacting with a system and is defined as a "specification of a role which is played by a user or any other system that interacts with the subject." [9]. Therefore, actors are suited for the purpose of showing process owners and customers.

The relationships between the stereotypes defined are described with the Association between classes. The OMG specifies an association as "a semantic relationship that can occur between typed instances" [9]. So there is no need to define an additional stereotype for the relationships between stereotypes.

As described in Fig. 2, a business process and its characteristics can be defined with six abstract top-level stereotypes, «Process Owner» and «Customer» (the specification of the stereotypes is listed in Table 1), «Business Process» (see Table 2), «Goal» (see Table 3) «Deliverable» (see Table 4) «Measure» (see Table 5). The semantics of the individual elements were described in greater detail in Section 3.

Table 1. Customers and Process Owners: Specification of Stereotypes

\begin{tabular}{|c|c|c|}
\hline Name & Customer & \\
\hline Base Class & Class & \\
\hline Description & $\begin{array}{l}\text { A customer is an internal or external role that receives products } \\
\text { business process [5]. }\end{array}$ & ervices from a \\
\hline Constraints & None & \multirow{5}{*}{ «External Customer» } \\
\hline Name & External Customer & \\
\hline Base Class & Customer & \\
\hline Description & An external customer is outside of the organisation. & \\
\hline Constraints & $\begin{array}{l}\text { An external customer has to be satisfied by at least one core } \\
\text { process which has to produce one or more deliverables. } \\
\text { context External inv: } \\
\text { self.CoreProcess->size() }>=1 \text { implies } \\
\text { self.Deliverable->size() >=1 }\end{array}$ & \\
\hline Name & Internal Customer & \multirow[b]{4}{*}{$\stackrel{\text { «Internal Customer» }}{\mathrm{O}}$} \\
\hline Base Class & Customer & \\
\hline Description & The internal customer is part of the organisation. & \\
\hline Constraints & $\begin{array}{l}\text { An internal customer has to be satisfied by at least one support } \\
\text { process or management process which has to produce one or } \\
\text { more deliverables. } \\
\text { context Internal inv: } \\
\text { self. SupportProcess->size() >= } 1 \text { or } \\
\text { self. ManagementProcess->size() >= } 1 \text { im- } \\
\text { plies } \\
\text { self.Deliverable->size() }>=1\end{array}$ & \\
\hline Name & Process Owner & \multirow{4}{*}{ «Process Ownem } \\
\hline Base Class & Actor & \\
\hline Description & $\begin{array}{l}\text { The process owner is concerned with the successful realisation } \\
\text { of a process, (...) and making sure that the complete process } \\
\text { works together [3], and with measuring it against target values. }\end{array}$ & \\
\hline Constraints & $\begin{array}{l}\text { A process owner is responsible for one or more processes. } \\
\text { context ProcessOwner inv: } \\
\text { self.BusinessProcess->size() }>=1\end{array}$ & \\
\hline
\end{tabular}


Table 2. Business Processes: Specification of Stereotypes

\begin{tabular}{|c|c|c|}
\hline Name & \multicolumn{2}{|l|}{ Business Process } \\
\hline Base Class & \multicolumn{2}{|c|}{ Class } \\
\hline Description & \multicolumn{2}{|c|}{$\begin{array}{l}\text { A business process is a group of tasks that together create a result of value to a cus- } \\
\text { tomer [3]. Three types of business process are differentiated: core, support and man- } \\
\text { agement processes [12]. }\end{array}$} \\
\hline Constraints & \multicolumn{2}{|c|}{$\begin{array}{l}\text { A business process is composed by at least one business process. } \\
\text { context BusinessProcess inv: } \\
\text { self. BusinessProcess->size }()>=1 \\
\text { A business process is designed by one or more detailed process diagrams. } \\
\text { context BusinessProcess inv: } \\
\text { self. DetailedProcessDiagram->size }()>=1 \\
\text { A business process is in the responsibility of one process owner. } \\
\text { context BusinessProcess inv: } \\
\text { self.ProcessOwner->size }()>=1 \\
\text { A business process wants to achieve at least one process goal. } \\
\text { context BusinessProcess inv: } \\
\text { self.ProcessGoal->size ()> }>1\end{array}$} \\
\hline Name & Core Process & \\
\hline Base Class & Business Process & \\
\hline Description & $\begin{array}{l}\text { Core processes concentrate on satisfying external custom- } \\
\text { ers. They directly add value to the organisation [12]. }\end{array}$ & \\
\hline Constraints & $\begin{array}{l}\text { A core process has to produce one or more deliverables to } \\
\text { satisfy one ore more external customers. } \\
\text { context CoreProcess inv: } \\
\text { self. External->size ()>= } 1 \text { implies } \\
\text { self.Deliverable->size() }>=1\end{array}$ & \\
\hline Name & Support Process & \\
\hline Base Class & Business Process & \\
\hline Description & $\begin{array}{l}\text { Support processes concentrate on satisfying internal } \\
\text { customers. They might add value to the customer indi- } \\
\text { rectly by supporting a core business process [12]. }\end{array}$ & \\
\hline Constraints & $\begin{array}{l}\text { A support process has to produce one or more deliverables } \\
\text { to satisfy one or more internal customers. } \\
\text { context SupportProcess inv: } \\
\text { self. Internal->size() }>=1 \text { implies } \\
\text { self. Deliverable->size() }>=1 \\
\text { A support process has to support one or more core proc- } \\
\text { esses. } \\
\text { context SupportProcess inv: } \\
\text { self.CoreProcess->size() }>=1\end{array}$ & \\
\hline Name & Management Process & \\
\hline Base Class & Business Process & \\
\hline Description & $\begin{array}{l}\text { Management processes concern themselves with manag- } \\
\text { ing the core processes or the support processes, or the } \\
\text { concern themselves with planning at the business level } \\
{[12] \text {. }}\end{array}$ & \\
\hline Constraints & $\begin{array}{l}\text { A management process has to produce one or more deliv- } \\
\text { erables to satisfy one or more internal customers. } \\
\text { context ManagementProcess inv: } \\
\text { self. Internal->size() >= } 1 \text { implies } \\
\text { Self.Deliverable->size() >=1 }\end{array}$ & \\
\hline
\end{tabular}


Table 3. Goals: Specification of Stereotypes

\begin{tabular}{|c|c|c|}
\hline Name & Goal & \\
\hline Base Class & Class & \\
\hline Description & Goals express intentions and capture reasons for a system to & \\
\hline Constraints & $\begin{array}{l}\text { A goal has at least one measure. } \\
\text { context Goal inv: } \\
\text { self.Measure->size() } \quad>=1\end{array}$ & \\
\hline Name & Process Goal & \multirow{4}{*}{ «Process Goal» } \\
\hline Base Class & Goal & \\
\hline Description & $\begin{array}{l}\text { Process goals support enterprise goals and represent the } \\
\text { intentions of a certain business process. }\end{array}$ & \\
\hline Constraints & $\begin{array}{l}\text { A process goal has to be achieved by one business proc- } \\
\text { ess. } \\
\text { context ProcessGoal inv: } \\
\text { self.BusinessProcess->size() = } 1 \\
\text { A process goal has to be supported by one or more enter- } \\
\text { prise goals. } \\
\text { context ProcessGoal inv: } \\
\text { Self.EnterpriseGoal->size() > }=1\end{array}$ & \\
\hline Name & Enterprise Goal & \multirow{4}{*}{ «Enterprise Goal» } \\
\hline Base Class & Goal & \\
\hline Description & $\begin{array}{l}\text { Enterprise goals represent the intentions of an organisa- } \\
\text { tion. }\end{array}$ & \\
\hline Constraints & $\begin{array}{l}\text { An enterprise goal supports one or more process goals. } \\
\text { context EnterpriseGoal inv support: } \\
\text { Self.ProcessGoal->size () >= } 1\end{array}$ & \\
\hline
\end{tabular}

Table 4. Deliverables: Specification of Stereotypes

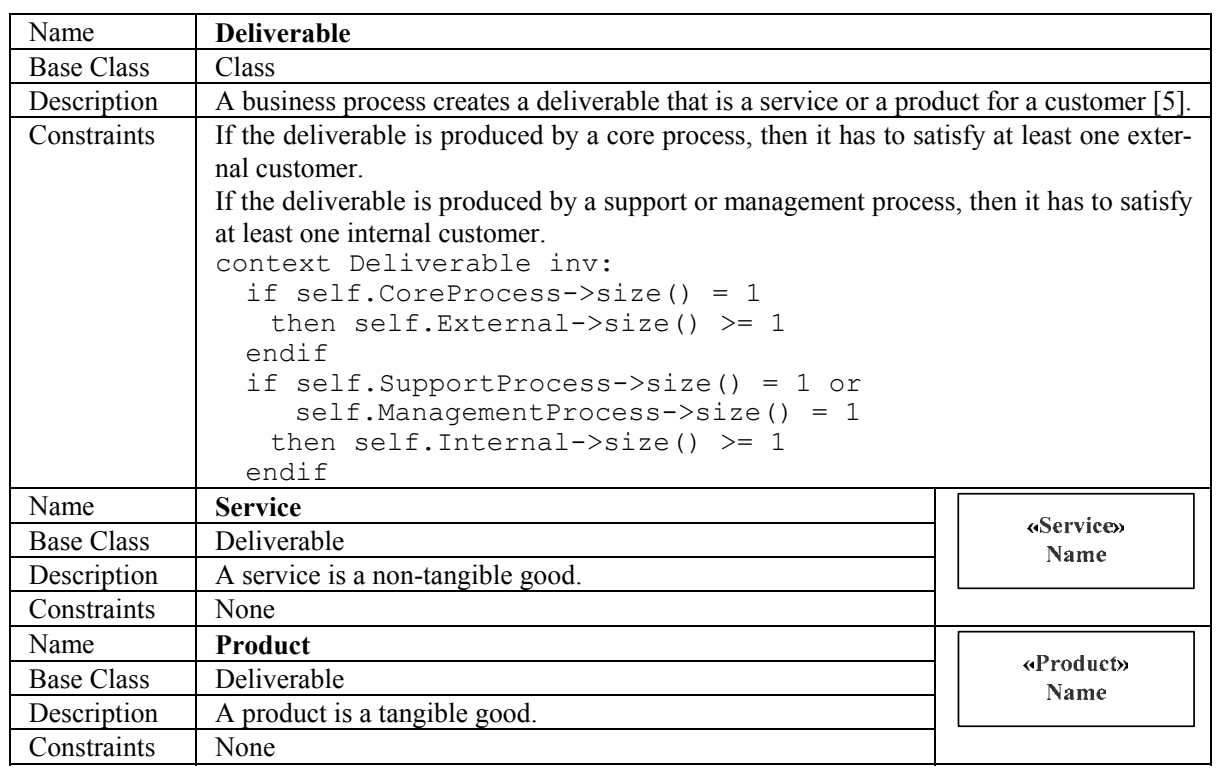


Table 5. Measures: Specification of Stereotypes

\begin{tabular}{|c|c|c|}
\hline Name & \multicolumn{2}{|l|}{ Measure } \\
\hline Base Class & \multicolumn{2}{|l|}{ Class } \\
\hline Description & \multicolumn{2}{|c|}{$\begin{array}{l}\text { A measure is a basis for comparison, a reference point against which other things can } \\
\text { be evaluated. }\end{array}$} \\
\hline Constraints & \multicolumn{2}{|c|}{$\begin{array}{l}\text { A Measure has to be assigned to a to be value, and is described by a unit. Both are } \\
\text { attributes. } \\
\text { context Measure inv: } \\
\text { self.Measure.AllAttributes->includes (unit) and } \\
\text { self.Measure.AllAttributes->includes (tobevalue) } \\
\text { A measure has to measure one goal. } \\
\text { context Measure inv: } \\
\text { self.Goal->size() }=1\end{array}$} \\
\hline Name & Qualitative Measure & \multirow{2}{*}{\begin{tabular}{|c|} 
«Qualita tive Measure» \\
Name
\end{tabular}} \\
\hline Base Class & Measure & \\
\hline Description & The measurement of descriptive elements (e.g. age). & \multirow{2}{*}{ 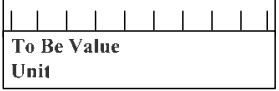 } \\
\hline Constraints & None & \\
\hline Name & Quantitative Measure & \multirow{2}{*}{$\begin{array}{c}\text { «Quantitative Measure» } \\
\text { Name }\end{array}$} \\
\hline Base Class & Measure & \\
\hline Description & Quantitative Measures are expressed in numerical values. & $|1| 1|c| c|c| c|c|$ \\
\hline Constraints & None & \begin{tabular}{|l|} 
To Be Value \\
Unii
\end{tabular} \\
\hline
\end{tabular}

\section{Example}

We demonstrate the practical applicability of the business perspective of the UML 2 profile for BPM in Fig. 3 with the example business process of an insurance company: the Processing of Claims business process. Fig. 3 shows that a business process based on the UML 2 profile for BPM can be grasped at a glance.

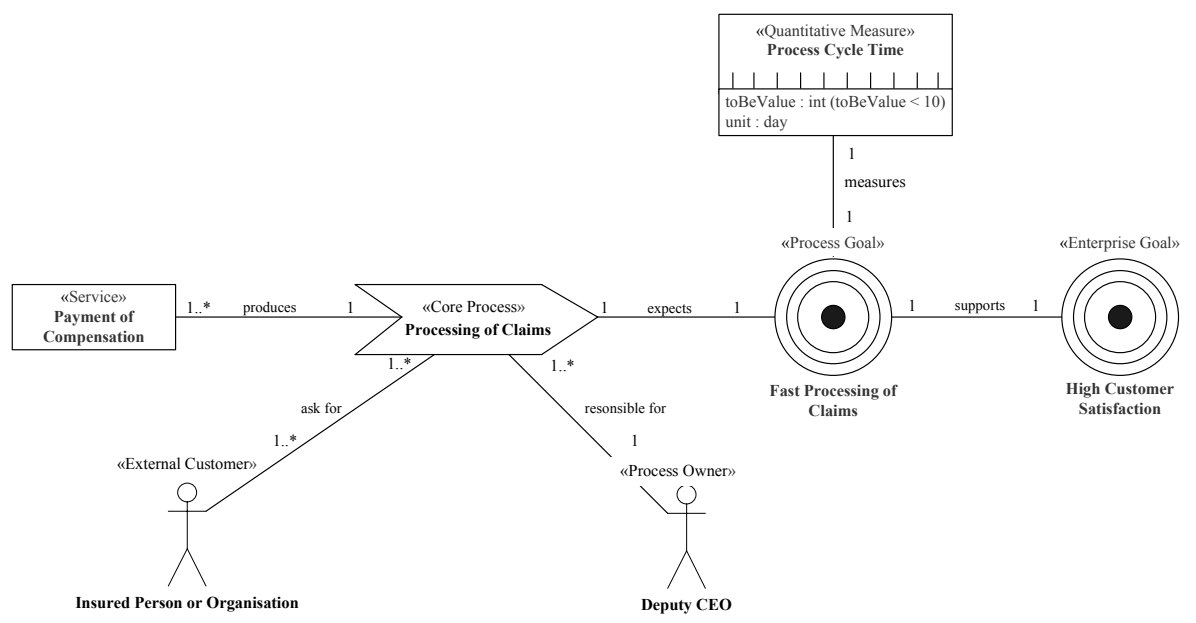

Fig. 3. Processing of Claims Business Process 
The Processing of Claims business process is a Core Process and therefore the Customer is External. The customer is an Insured Person or Organisation. Beside the proposal business process, the processing of claims business process is the most important process in an insurance company. Therefore, a very powerful position is required for the Process Owner. In this example it is the Deputy CEO. Fast Processing of Claims is the Process Goal that supports the Enterprise Goal, High Customer Satisfaction. The Quantitative Measure is the Process Cycle Time and measures the achievement of the process goal. The To Be Value of the cycle time is less than 10 Days, the Unit of the measure.

\section{Related Work}

There are already some UML profiles for business process modelling available in the current literature. The profiles focus primarily on the sequential flow of the business process and represent comprehensive business process concepts only partly. All of the existing profiles are based on UML 1.4., whereas the UML profile developed in this paper is based on UML 2.

The UML profile for business modeling of the OMG [7] is defined in the UML 1.4 specification and embodies the object-oriented approach for business engineering developed by Jacobson et al. [5]. The model consists of two views, an external and an internal view. The external view is described by the use case model, the internal view by the object model. The model lacks a detailed process flow with a sequence of activities, but also business context.

Johnston extended the UML profile for business modeling of the OMG [7] with goals and events, and an activity diagram to represent the process flow. It is called the rational UML profile for business modeling [6]. This UML profile is a component of the Rational Unified Process ${ }^{\circledR}\left(\mathrm{RUP}{ }^{\circledR}\right)$. It presents a UML language for capturing business models and is supported by the business modelling discipline in the RUP.

The UML profile for business modelling in [14] proposes a basic meta-model covering a business process, its resources, and goals. The profile gives a basic overview of the process, and provides a detailed description of the process flow with ActionStates (from ActivityGraphs).

The UML profile for business modelling in [15] focuses on the integration of business processes into software development. The profile maps between business concepts and software artefacts. Therefore, the profile describes the process flow in a very detailed way, and in addition adds goals, measures and resources, but lacks more advanced concepts like customers, process types or process owners.

The UML profile for modeling workflow and business processes in [1] is closely related to UML activity diagrams. The profile targets the modelling of business process architectures and other activities of concurrent processes. It provides dynamic semantics for these modelling concepts which can be used as a basis for the construction of automated analysis tools which provide performance simulations for the established models. The profile contains only basic concepts like activities and participants, such as actors and resources. 


\section{Conclusion}

In this paper, we have developed a UML 2 profile for BPM targeting software developers to view business processes in their own notation. The profile provides two complementary perspectives, the business perspective and the sequence perspective. The sequence perspective refines the business perspective and describes the detailed flow of the process. The business perspective presents the business process from a wide angle by integrating aspects like goals, customers, deliverables, or process types etc. In order to capture these characteristics, we have developed a meta-model for the business perspective, described with stereotypes. The UML 2 profile for BPM was tested with an example business process.

\section{References}

1. Bochmann, G. v.: A UML profile for modeling workflow and business processes. http://beethoven.site.uottawa.ca/dsrg/PublicDocuments/Publications/Boch00d.pdf $(8 / 8 / 05)$.

2. Business Process Management Initiative (BPMI): Business Process Modeling Notation $(\mathrm{BPMN}), \quad$ Specification Version 1.0, May 3, 2004, http://www.bpmn.org/Documents/BPMN\%20V1-0\%20May\%203\%202004.pdf (8/8/05).

3. Hammer, M.: Beyond Reengineering - How the process-centered organization is changing our work and our lives. Harper Collins Publishers, 1996.

4. Harrington, J.H.: Business Process Improvement - The breakthrough strategy for total quality, productivity, and competitiveness. McGraw-Hill, 1991.

5. Jacobson, I., Ericson, M., Jacobson, A.: The Object Advantage - Business Process Reengineering with Object Technology. ACM Press, Addison-Wesley Publishing, 1995.

6. Johnston, S.: Rational UML Profil for Business Modeling. http://www128.ibm.com/developerworks/rational/library/5167.html\#author1 (8/8/05).

7. Object Management Group: UML 1.4 Specification http://www.omg.org/docs/formal/0109-75.pdf $(8 / 8 / 05)$.

8. Object Management Group: UML 2.0 OCL Specification http://www.omg.org/docs/ptc/03-10-14.pdf (8/8/05)

9. Object Management Group: UML 2.0 Superstructure http://www.omg.org/cgibin/doc?ptc/2004-10-02 (8/8/05).

10. Object Management Group: Business Process Definition Metamodel http://www.bpmn.org/Documents/BPDM/OMG-BPD-2004-01-12-Revision.pdf (8/8/05).

11. Object Management Group: MDA Guide Version 1.0.1 http://www.omg.org/docs/omg/03-06-01.pdf (8/8/05).

12. Ould, M.: Business Processes - Modelling and Analysis for Re-engineering and Improvement. John Wiley \& Sons, 1995.

13. Scheer, A.-W.: ARIS - Business Process Modeling. Springer Verlag, 1999.

14. Sinogas, P., Vasconcelos, A., Caetano, A., Neves, J., Mendes, R., Tribolet, J.: Business Processes Extensions to UML Profile for Business Modeling. Proceedings of the International Conference on Enterprise Information Systems, 2001.

15. Tyndale-Biscoe, S., Sims, O., Wood, B., Sluman C.: Business Modelling for Component Systems with UML. Proceedings of the $6^{\text {th }}$ International Enterprise Distributed Object Computing Conference (EDOC '02), IEEE Press, 2002. 